A autora analisa a problemática de crianças seqüestradas e dos bebês roubados durante a última ditadura militar na Argentina à luz da teoria lacaniana apontando questões relativas ao nome próprio e ao Nome-do-pai.

Nome próprio; terrorismo de estado; sistema de parentesco.

FROM THE PROPER NAME TO THE WRIGHTING OF THE NAME

The autbor analyses the problems of kidnapped children and stolen babies during the last military dictatorsbip in Argentina under the light of the Lacanian theory, pointing out questions related to the proper name and the Name of the fatber. Proper name; state terrorism; kinsbip system.

\section{DO NOME PRÓPRIO \\ À ESCRITA \\ DO NOME}

\section{A problemática das crianças seqüestradas e dos bebês} roubados $^{1}$ durante o Terrorismo de Estado estabelecido pela última ditadura militar na Argentina (1976-1983)

Alicia Lo Giúdice

"Que renuncie quem não possa unir seu borizonte à subjetividade de sua época" Jacques Lacan

"Se compreender é impossível, conbecer é necessário" Primo Levi

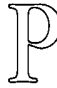

rimo Levi, sobrevivente do campo de destruição nazista de Auschwitz, em seu livro Si esto es un bombre, afirma que, após a liberação tornou-se premente a necessidade de falar "aos demais" para que soubessem do ocorrido, impulso imediato e violento mais importante

Psicanalista, professora adjunta da Facultad de Psicologia, Universidad de Buenos Aires. Doutoranda Universidad de Buenos Aires. 
que outras questões elementares, é assim que escreve este livro, como um "modo de liberação interior"; sua escrita, esclarece, é fragmentada, não construída como uma sucessão lógica, mas por uma ordem de urgência.

Trabalho de escrita que inicia sendo ainda prisioneiro e que retoma quando regressa à Itália. Livro rejeitado por vários editores, finalmente publicado em 1947, mas adquirindo notoriedade apenas dez anos depois, com sua reimpressão.

Afirma que "talvez não se possa compreender tudo o que ocorreu ou não se deva compreender, porque compreender é quase justificar. Com isso, quero dizer que 'compreender' uma proposição ou um comportamento humano significa (no sentido etimológico) contê-lo ou conter o autor, pôr-se em seu lugar, identificar-se com ele. Mas nenhum homem normal poderá jamais identificar-se com Hitler, Goebbels (...) e infinitos outros. Isso nos desorienta e ao mesmo tempo nos consola, porque talvez seja desejável que suas palavras (e também, infelizmente, suas obras) não cheguem nunca a tornarem-se compreensíveis.

...Não podemos compreendê-lo, mas podemos e devemos conhecer onde nasce e estarmos vigilantes. Se compreender é impossível, conbecer é necessário, porque o ocorrido pode voltar a ocorrer, as consciências podem ser seduzidas e obnubiladas novamente; as nossas também. Por isso meditar sobre o que ocorreu é dever de todos" (Levi, 1995, p.208).

Jorge Semprún, escritor, sobrevivente do campo de extermínio de Buchenwald, em seu livro A escrita ou a vida pergunta-se: mas pode-se contar? Poderá ser contado alguma vez? E surge a dúvida diante da impossibilidade de contar "não porque a experiência vivida seja indizível, foi 'invivível', algo totalmente diferente".

Afirma que talvez sempre possa expressar-se tudo, mas podese ouvir tudo? Imaginar tudo? Reconhece o horror dos soldados que o liberaram, e entende-os, pois não havia sobrevivido à morte, não a havia evitado, havia percorrido seus caminhos, havia se perdido nestes e voltado a encontrar-se, era um "aparecido". "Em todas as matanças da história há sobreviventes, mas não havia e jamais haveria sobreviventes das câmaras de gás nazistas" (Semprún, 1995). Daí a angústia de não se tornar crível, porque não se está morto, precisamente porque se sobreviveu.

Semprún abandona, ao regressar, o livro que em vão estava tentando escrever. Não podia continuar escrevendo-o, pois o fazia à custa de sua própria sobrevivência, pois a escrita remetia-o à experiência mortífera. Escrever sobre o vivido era para ele, nesse momento, negar-se a viver. Decide então pelo silêncio da vida, em oposição à "linguagem assassina da escrita". Escolheu o esquecimento, a estratégia da amnésia voluntária, cruelmente sistemática "tornei-me outro para poder continuar sendo eu mesmo".

Passaram-se 40 anos até que pudesse retomar a escrita. Semprún reconhece que, se para Primo Levi a escrita era libertadora e 
apaziguava sua memória, para ele o efeito era afundar-se novamente na morte.

Dois escritores forneceram-nos seu testemunho e seu pensamento, que nos falam de sua posição subjetiva diante do atravessamento do horror. Primo Levi, para viver, precisa escrever imediatamente; para Jorge Semprún a escrita significava a morte e somente 40 anos depois a escrita se impõe. Ambos são sobreviventes de experiências extremas deste século e deste milênio. E é justamente Primo Levi quem se dá conta de que os métodos do nazismo continuam vigentes, entre outras situações, no desaparecimento de pessoas na Argentina durante a última ditadura militar, entre 1976 e 1983.

O Terrorismo de Estado estabeleceu um método de perseguição política inédito que produziu o "desaparecimento forçado de pessoas" de forma sistemática, realizado por grupos específicos, nos quais estavam envolvidos todos os setores do poder.

O "desaparecimento forçado de pessoas" pode ser considerado como uma catástrofe social que instala o horror do sinistro como forma de vida e produz dano psíquico não só nos afetados diretos, mas à sociedade em seu conjunto, pois o sistema legal deixa de ter vigência e produz uma ruptura dos laços que sustentam o social.

O trauma vivido, verdadeiro genocídio, afeta o tecido social, tornando-se um trauma histórico. Genocídio é um termo empregado por Raphaël Lemkin, fundamentado no nazismo, e é definido como um crime contra o direito das pessoas que é cometido em tempos de paz ou de guerra. É o exercício criminal da soberania estatal.

Posteriormente, pôde-se saber que os referidos desaparecimentos podiam incluir uma família inteira, e gerou-se um fato ainda mais sinistro, inédito na modernidade, que foi a apropriação de bebês nascidos no cativeiro de suas mães seqüestradas e desaparecidas. Esta apropriação foi realizada ilegalmente, na maior parte por pessoas ligadas à repressão, ou os bebês dados como $\mathrm{NN}^{2}$ a instituições hospitalares.

Sobre estas crianças foi exercida violência, dado que:

$\square$ foram abruptamente separadas de seus pais, já que não foram abandonadas, mas roubadas;

$\square$ houve sonegação de identidade, incluindo mudança de nome e sobrenome, em alguns casos mudança de idade, simulação de parto com falsificação de certidão de nascimento. Adoções aparentemente legais, crianças que apareciam abandonadas e eram tratadas como $\mathrm{NN}$;

$\square$ crianças assassinadas no seqüestro;

$\square$ bebês assassinados no ventre materno;

$\square$ tortura e humilhações a mulheres grávidas;

$\square$ convivência com pais falsos que obtêm vínculo baseado no desaparecimento e posterior assassinato dos pais.

À violência imposta foi acrescentada a cuidadosa tarefa daqueles que realizaram a apropriação e dos aparelhos do Estado, de apagar toda ligação com a origem.

Uma menina de 23 meses é seqüestrada junto com seus pais no mês de maio de 1968 , em um país fronteiriço no qual moravam havia algum tempo. A avó materna inicia a busca da neta e de seus pais, sem saber muito bem o que havia ocorrido. Une-se à Associação de Avós da Praça de Maio e seguem-se anos de incerteza e de luta para conhecer o paradeiro da neta, até que em 1980, Clamor, entidade brasileira dedicada à defesa dos direitos humanos, entrega às Avós da Praça de Maio uma foto 
com uma denúncia sobre uma menina que acreditavam ser filha de desaparecidos, mas que constava como filha legítima de um integrante da polícia.

Ao seqüestrá-la e trazê-la novamente para Buenos Aires, o apropria$\operatorname{dor}^{3}$ (que fazia parte do aparelho repressivo) e sua esposa voltam a registrá-la no Registro Civil como filha legítima e como recém-nascida. O notável da situação é que, de acordo com o que se sabe através das denúncias efetuadas, a menina insistiu tanto em ser chamada por seu nome, sendo este o único ao qual respondia, que conseguiu conservá-lo, ainda que na nova documentação constasse o segundo.

Formulamos a hipótese de que em sua insistência em ser chamada por seu nome, em dizer "sou tal..." está firmando-se em sua particularidade, ela decide-se por si mesma, a partir do nome outorgado pelos pais, que, em função do Nome do Pai, inscreve, traça uma marca identificatória simbólica, que os que realizaram a apropriação querem que apague, mas logo aceitam, talvez acreditando que conservando somente o nome não conserva sua ascendência geracional, podendo assim falsificar o atual e sua descendência. Ao incluí-la violentamente em uma nova genealogia que renega a de origem parece que o mandato é "não seja você, mas o que eu quero que você seja". Trata-se de uma filiação narcisista que renega a filiação instituída pelos pais.

Para o direito o vínculo de filiação é um vínculo constituído pelas instituições jurídicas. A filiação é um conceito que deve ser tratado como "princípio político de organização" (Legendre, 1997) que permite o enlaçamento do biológico, do social e do subjetivo. A genealogia aponta para o conjunto dos sistemas institucionais fabricados pela humanidade para sobreviver e difundirse. $\mathrm{O}$ direito romano fala em instituir a vida, instituir implica a normalização, cuja exigência será a existência de um modelo de legalidade que garanta a conservação da espécie. A arte de governar é a arte de tramar uma legalidade para fazer nascer uma pessoa, que possa subjetivar-se e fazer com que a vida possa transcorrer até a morte. A espécie apresenta-se ao sujeito humano através da genealogia. É a lei que determina um pai a um filho em virtude de uma presença legal que assim o estabelece. A humanidade é uma sucessão de pais e filhos, e a filiação é uma montagem da cadeia humana. Como vemos, o que foi formulado em relação à filiação é alterado no caso da apropriação de menores.

Apesar de mudanças e perdas de pistas, finalmente a menina pôde ser localizada após um minucioso seguimento de rastros que outros acreditavam ter apagado para sempre. Era o ano de 1980, e a avó materna a vê sem poder identificar-se. Relata: "Quando a vi de costas, com suas pernas gordinhas e seus cachos de sempre, a vi de costas, mas a reconheci, tinha 4 anos".

Assim inicia um caminho árido para reconstruir sua história e procurar provas para a queixa judicial. Para que esta se tornasse efetiva, ainda tiveram que esperar a posse do governo constitucional, em dezembro de 1983, que poderia oferecer garantias à menina, porque o temor era que os que se apoderaram dela, ao saberem da queixa judicial, tentassem sair do país.

A avó materna pensava que com a denúncia do seqüestro e com a certidão de nascimento com que contava, a menina poderia voltar a sua família, mas depara-se com o fato de que havia a documentação falsa que a certificava como filha legítima do apropriador, na qual a idade tinha sido modificada. Em lugar de estar registrada com sua idade cronológica real, aparecia com dois anos a 
menos, ou seja, havia sido registrada como recém-nascida no ano do seqüestro, com data de nascimento falsa.

Começa assim uma longa luta judicial para comprovar a identidade desta menina. Pedem-se à Justiça as análises possíveis de identificação, incluindo a de compatibilidade sanguínea, a partir da qual surge a confirmação de sua identidade, com um índice de inclusão na família que a procurava de $99,80 \%$. As referidas provas, a partir da criação do Banco Nacional de Dados Genéticos, têm o valor de documento público, tornando-se equivalentes às impressões digitais.

Anteriormente foram realizados estudos ósseos para comprovar sua idade, e os mesmos confirmavam a idade declarada pelo apropriador. Sua estrutura óssea não se desenvolveu de acordo com a idade.

Mesmo após a confirmação de sua identidade, a restituição não foi outorgada. A menina continuava ignorando a situação, mas os que se apropriaram dela avisam-na de que uma senhora louca fazia-se passar por sua avó e queria roubá-la. Quando estes fatos tornam-se públicos através da mídia, na casa em que a menina vivia passam a não receber jornais nem revistas e também a proíbem de ver televisão, mas seus companheiros da escola contam-lhe que sua avó estava à sua procura.

Diante da negativa do juiz responsável em modificar a situação desta menina, a família decide apelar a outras instâncias legais para conseguir a restituição. No mês de dezembro de 1984, a Câmara de Apelação no Criminal e Correcional Federal decide por sua restituição e o dr. Andrés D'Alessio, que a presidia, encarrega-se da entrega da menor a sua família, no Palácio da Justiça, contando-lhe o que ocorrera e os motivos pelos quais iria morar com a mãe de sura mãe.
Sua primeira reação foi choro e gritos, explicam-lhe quem são seus familiares diante de sua irritação e desconfiança. Mostram-lhe fotos de quando era pequenina nos braços dos pais, mas sua desconfiança persiste porque diz que as fotos são novas. Sua avó explica que são novas porque foram ampliadas recentemente, a partir das originais que estavam esperando-a em sua casa. Observando uma das últimas fotos da época em que morava com seus pais, comenta que era bastante parecida com uma que tinha na casa em que morava. A avó acredita que deve ser uma foto tirada depois do seqüestro.

Em relação ao apropriador, diz: "Ele não mentiu para mim". Mas depois de algum tempo muda de tom e diz: "Ele não mentiu para mim, não é?" Enquanto isso, olhava fotos, chorava em alguns momentos, então a avó menciona o nome pelo qual chamava seu pai, que era uma deformação do mesmo, pois em função de sua idade não sabia pronunciá-lo corretamente. Ao escutá-lo a menina tem uma crise de choro, começa a chorar aos gritos e em seguida adormece. Ao acordar, aceita ir para casa com sua família.

Sai do Palácio da Justiça de mãos dadas com o dr. D'Alessio e parte para a casa de sua avó materna, na qual examina fotos e parece reconhecer alguns lugares, dos quais se aproxima sem pedir ajuda; é a casa na qual tantas vezes esteve com seus pais quando era pequenina. Nesta noite, dorme tranqüila.

A luta judicial logo reaparece, a partir do pedido de visita dos que realizaram a apropriação, ao qual a família se opõe pela situação à qual foi submetida e porque pôde-se provar que o apropriador pertenceu a um dos "grupos de tarefas" do Terrorismo de Estado, formando parte de um centro clandestino de detenção (campo de concentração e extermínio). Após poucos me- 
ses da restituição, o juiz que conserva a tutoria obriga a menina a ter uma entrevista com os que se haviam apropriado dela, apesar de isso ser contra sua vontade. Nesta, pergunta-lhes porque mentiram para ela e onde estão seus pais. Eles continuam afirmando que são seus pais biológicos, mas diante de sua insistência em perguntar pelos pais, o apropriador comete um lapso e diz: "Eu não conheci seu pai".

Cabe esclarecer que sempre negaram-se a realizar exames para provar a referida consanguinidade. Posteriormente, a Câmara Federal, aceitando o dano psíquico ao qual a expunha, não volta a permitir visitas. O casal que tinha se apoderado da menina é condenado à prisão, inafiançável para o homem, mas ambas as penas nunca foram executadas, ficando em suspenso. Apesar de que a restituição tenha ocorrido no ano de 1984, apenas em março de 1988 entregam-lhe os documentos de identidade com seu nome e sobrenome legítimos.

Uma menina é seqüestrada, "desaparece" com seus pais. Em um mesmo ato de apropriação fazem-na desaparecer de uma linhagem e de um sistema de parentesco para fazê-la "aparecer", mas pertencendo a outro. Modificam sua idade, seu sobrenome, simulam um parto, falsificam a certidão de nascimento, mas ela consegue reter seu nome. Submetem-na a uma situação na qual o familiar torna-se estranho e o estranho familiar, que nos recorda o que foi trabalhado por Freud em "O sinistro". Forçam-na a apagar todo traço de sua origem; despojando-a de seus pais, obrigam-na a romper com sua história, com seu passado, com os ideais familiares, com suas referências tempoespaciais, com suas marcas identificatórias.

No ato de apropriação, a menina é violentamente incluída em um sistema de parentesco por meio de uma filiação narcisista, amparada no Terrorismo de Estado, que aparece como prolongamento do próprio narcisismo do apropriador e que no triunfo sobre os pais deve perpetuar-se para além de seu desaparecimento. Produz-se uma fratura geracional, uma vez que ao apropriar-se dela submetem-na a uma relação que renega o ocorrido e se baseia no assassinato dos pais, não da forma descrita por Freud em Totem e tabu, no qual o rito sacrificial, não individual, mas social, funda a cultura. Esta falsificação cria uma situação perversa, e a menina corre o risco de funcionar como objeto fetiche, interpretando para sobreviver o papel de objeto que lhe impõem, com o risco psíquico que implica.

Que lugar ocupa o assassinato nesta situação? Trata-se de uma fragmentação extrema do discurso normativo tão caro às instituiç̧ões. Parece substituído por uma autonomia normativa que promove a des-metaforização da Lei e aparece um novo tipo de desumanização, uma vez que os novos homicidas são criminosos impunes, e, no entanto, não são loucos.

Com o surgimento do nazismo e de sua prática de extermínio, o crime deixou de ser penalizado, ou seja, produziu-se uma suspensão do proibido. A noção de culpa estabelece uma ponte entre a ordem social da normalização e a ordem normativa do sujeito. O fato de que o sujeito que cometeu delitos durante a ditadura militar tenha em seguida se beneficiado com as leis de Ponto Final e Obediencia Devida da democracia e por último com o Indulto não quer dizer que o crime tenha desaparecido. A autonomia normativa deve ser tratada como sintoma social, e não como a causa da doença da identidade moderna. Em cada cultura a humanidade constrói uma representação legal do 
homicídio, esforçando-se assim para dar-lhe um estatuto na palavra e pôr em cena, desta forma, a proibição de matar. Quando deparamos com fatos genocidas, ficamos diante do horror que nos expõe aos limites do que é passível de ser falado.

Conheço essa menina nos últimos meses de 1985. Naquele momento a avó materna começava a pensar na possibilidade de uma consulta. A menina adianta-se e pede a um familiar que me conhecia para iniciar uma análise comigo. Tinha 9 anos e 4 meses.

Comparece à primeira consulta com sua avó. Permanece quase em silêncio, mas muito atenta, deixando a avó falar. Tem à sua disposição brinquedos, material gráfico e massa para modelar, mas não os usa.

$\mathrm{Na}$ segunda entrevista pega uma folha de papel em branco e cobre-a com tinta plástica até a metade, deixa-a e não faz nenhum comentário. Proponho abrir um espaço e um tempo para avaliar se seria possível realizarmos um trabalho analítico juntas. Assim, a cada encontro vamos combinando o horário do próximo.

É importante esclarecer que para sua segurança pessoal era transportada em carro oficial com custódia policial, dadas as ameaças de morte feitas pelo apropriador ao efetivar-se a restituição. A custódia manteve-se até a entrega dos documentos legítimos.

Após algumas entrevistas, proponho um horário. Como sua avó não pode vir neste horário, ela pede que outra pessoa a acompanhe, pois quer vir. A partir deste momento entra sozinha no consultório, com o tempo encarrega-se de trazer o dinheiro dos honorários e dá um jeito para que eu não tenha o menor contato com sua família.

Começam a aparecer outros aspectos que chamam a minha atenção: está absolutamente atenta a tudo que me diz respeito, a meu aspecto, a meus gestos, aos objetos do consultório. Poderia registrar até mesmo a menor mudança ou cada um dos objetos novos, fazendo perguntas a respeito deles. Também registrava odores e sons ínfimos. Parecia que nada escapava a sua observação.

Em uma sessão usa uma caneta nova. Esta caneta é quebrada por outra paciente, e eu a reponho. Na sessão seguinte ela a utiliza e comenta: "Você comprou uma nova, não é?" Em outra ocasião, um par de horas antes de atendê-la tenho uma entrevista com o pai de outro paciente que é dentista. $\mathrm{Na}$ sua sessão, ao entrar, diz: "Que cheiro de dentista. Veio um aqui, não é?” Nenhum dos pacientes anteriores tinha notado o cheiro.

Após as férias de verão, tínhamos combinado o dia para reiniciar as sessões, que seria no meio da semana, mas na segunda-feira ela me telefona, não no consultório, mas em minha casa e, com voz chorosa, diz que foi ao consultório, e eu não estava. Recordo-lhe o que havíamos combinado, mas ela não me escuta, continua queixando-se e chorando, repetindo: "Se eu fui, por que você não estava?"

Ao retomar em sessão a pergunta "por que você não estava?", lembra-se de que em suas férias, que transcorrem no país do seqüestro, ao entrar em um parque com uma amiga e acompanhada pelas respectivas avós, começa a falar como um bebê. Era o parque onde foi seqüestrada enquanto passeava com sua mãe.

Em outro momento surge a proposta de desenhar a partir de um ponto qualquer da folha e, alternando-nos, cada uma deve inventar um desenho. Pede-me que eu comece. Faço um traço, faz um desenho, assim a folha vai povoando-se de pequenos desenhos até que começa a escrever: a primavera terminou e chega o inverno e passaram-se 
nove meses e chegou o inverno e passaram-se nove meses e chegou o verão. Pergunto-lhe sobre a alteração das estações e pelos nove meses. Fica surpresa e fala de duas gravidezes e da confusão com os tempos. Começa a falar da modificação de sua idade.

Em seguida começa uma atividade que chama "las papas" na qual deve-se desenhar linhas curvas e deve-se passar entre elas com uma caneta e quem passa por cima é uma "papa", a que tem mais "papas" perde. Brincando com a homofonia "papa" e "papai" 5 começa a escrever a letra inicial de seu nome e sobrenome, rasura a folha e escreve novamente. Depois quer escrever seu nome e sobrenome em sua pasta de desenhos. No início das entrevistas, eu sugeri que o fizesse, mas naquele momento ela hesitou e não o fez.

Em pouco tempo obtém os documentos de identidade com seu nome e sobrenome e é neste momento que pede para deixar a análise e, antes de ir embora, pede-me um cartão com meu nome e meus dados para o caso de precisar falar comigo. Nesta época já começa a circular sozinha e pensa em diversas formas para se virar: leva fichas de telefone, a chave de casa pendurada no pescoço para não a esquecer, e memoriza números de telefone e endereços de familiares e amigos.

Telefona-me depois de alguns meses, depois que o apropriador a espera em frente de sua casa e a chama, ela sai correndo, mas antes lhe mostra a língua: "Foi a única coisa que me ocorreu". Pede para ver o juiz a fim de solicitar-lhe que faça algo para que não a incomodem, mas o juiz responde que terá de se virar sozinha, porque "assim é a vida". Neste momento, ela tinha 12 anos.

Cabe esclarecer que durante o tempo da análise, sua figura modificou-se notavelmente, cresceu e estilizou-se.

Em 1990 volta a procurar-me, outras questões trazem-na desta vez. Agora conta com quase 14 anos, iniciou o colégio secundário, suas preocupações estão ligadas a sua vida social, às perguntas sobre a sexualidade, sua reacomodação familiar, sua relação com sua avó. Também aparecem novas perguntas, sonhos, lembranças. O árduo trabalho de luto sobre seus pais desaparecidos continua. Após um ano e meio pede novamente para deixar a análise por um tempo. Diz que se brigar muito com sua avó talvez volte mais rápido. Seu olhar está voltado para os pares e para a busca de novos interesses.

\section{ALGUMAS CONSIDERAÇÕES}

Jacques Lacan articulou a função paterna à função do nome na estrutura da metáfora paterna, formulando que o nome do pai é para o desejo da mãe o que o desejo da mãe é como significado ao sujeito. Assim, o nome do pai é agente de transformação na cadeia e nexo entre eles. A Metáfora Paterna, a função do nome do pai, é a indução do que denomina "significado ao sujeito", ou seja, 
a produção de um novo sujeito. No Seminario XXIII, Le sinthome afirmará que o Nome do Pai sustenta-se no Pai do Nome, pois há um suposto de que há na origem um autor que é autoridade de doação para o nome primeiro de todas as coisas.

Lacan, tomando as contribuições da antropologia estrutural de LéviStrauss, fará da estrutura nominal o eixo mesmo da função paterna. Se miticamente o pai pode não ser mais que um animal, o pai primordial, o pai anterior à proibição do incesto não pode estar antes do advento da cultura; e de acordo com o mito do animal, sua satisfação não tem limite: o pai é o chefe da horda. Mas que o chamem Totem é o que torna imprescindivel, em um segundo momento, pôr no nível do pai a função do nome: "O nome é essa marca e a abertura à leitura (...), no significante existe este lado que espera a leitura e é nesse nível que se situa o homem" (Lacan, 1971).

Para constituir-se subjetivamente, o bebê se identificará primeiramente a seus pais, deles receberá uma marca simbólica, traço identificatório que lhe permitirá ser. Será marcado com um nome, inscrição simbólica, que não é apenas nome, pois inclui as etimologias do sobrenome, a novela familiar, pois alguém se nomeia como foi nomeado e, ao nomear-se, nomeia sua relação com seus progenitores, aqueles que o incluíram na ordem das gerações. Identificação, não identidade, que é uma inscrição inconsciente que tem eficácia simbólica, que particulariza e impede a repetição do idêntico. Em cada inscrição é marcado o lugar que o sujeito ocupa na ordem das gerações que é único e que abre o caminho a novos elos no sistema de parentesco.

Se esta menina retém seu nome, mostra uma inscrição simbólica, mas, ante a presença de um sujeito que se impõe, amparado pelo Terrorismo de Estado, não como pai, mas como chefe da horda, e que produz uma marca, não no nome, mas no corpo, provoca o fenômeno psicossomático de redução no seu crescimento ósseo em dois anos, de acordo com o decidido pelos que apropriaram-se dela.

Para a psicanálise o traumatismo é uma efração que o sujeito sofre e evoca uma causalidade por fora do sujeito, aparece assim a idéia de inocência do sujeito, já que não se escolhe o traumatismo. Freud falará de neuroses traumáticas, neuroses de guerra e psiconeurose de defesa, põe-nas em série, e aparecem como inscrições do gozo... Nelas o que está em jogo é a efração de algo que não é o sujeito. O perigo de que se trata é da libido. Na neurose traumática o perigo vem de fora e põe a vida em jogo, pois um fato real irrompe.

Lacan, para quem o real vai do trauma ao fantasma, postula que só há o fato porque pode ser dito, ou seja, os fatos são discursivos, assim introduz novamente o subjetivo nos fatos. $O$ trauma é uma exceção ao ser um fato que se impõe fora do discurso, é um fato sem dito. Daí o assombro que provoca: pode ocorrer um silêncio seguido por um falar ininterrupto, já que o trauma é relatado uma vez após outra, em uma tentativa de inscrição simbólica, ou seja, é uma tentativa de inserir este real indizível no simbólico.

O trauma impõe um gozo, e este é o sentido que lhe dá Freud ao evocar a efração do princípio do prazer, a efração da paraexcitação que deixa fora de jogo a homeostase do corpo. No traumatismo o gozo que surge não é fálico, e Lacan o escreverá gozo Outro. Aqui será o gozar Outro, ou seja, a aparição de um gozo sem significante, fora do Outro do significante, fora do simbólico, mas não fora do corpo. Daí surge a idéia de que o corpo possa funcionar 
como outro, diferente do corpo como lugar do Outro do significante. É neste ponto, em que o corpo, no trauma, fica afetado de uma maneira singular, que podemos introduzir o caso desta menina, que apresenta o fenômeno de detenção do crescimento de acordo com a idade imposta pelo apropriador, já que este fenômeno não questiona o desejo do Outro, mas opera um esquivamento do Outro.

Não podemos considerar o fenômeno psicossomático como um grito, pois este supôe um chamado ao Outro, e Lacan situa estes fenômenos do lado do hieroglífico, da ordem do escrito, escritura no corpo da ordem do enigma. A incorporação da estrutura da linguagem tem sobre o corpo o efeito de separar o corpo do gozo, seu esvaziamento e o fato de que este gozo fique reservado às zonas erógenas do corpo delimitadas por Freud. Neste tipo de fenômeno, o gozo, separado do corpo, volta a entrar, retorna no corpo. O próprio do fenômeno psicossomático é a maneira de esquivar-se do outro do significante, mas não se esquivar do corpo como Outro, ao esquivar-se do Outro do significante, o Outro do corpo fica impresso, marcado e evoca o conceito de complacência somática em Freud. Aqui é o corpo como Outro o que vem tomar nota do que teve lugar no acontecimento traumático.

Lacan, na Conferência de Genebra de 1975 , considera o corpo no caso do fenômeno psicossomático, como marca que revela o nome próprio e evoca o que os místicos chamam a assinatura das coisas. Se Lacan fala do fenômeno psicossomático como marca que revela o nome próprio, já que a função da marca é ser uma assinatura, não é preciso introduzir as antinomias do nome próprio. Existe o nome próprio que se faz com o Nome do Pai, e aquele que se faz sem o Nome do Pai. 
Eric Laurent interpreta essa marca como nome próprio feito sem o Nome do Pai, o importante aqui é o real do gozo. Segundo este autor nos encontraríamos diante de um nome próprio feito não com o Nome do Pai, mas com o gozo que seria o verdadeiro nome próprio, o nome próprio estaria em oposição ao Nome do Pai, seria um nome composto com um cifrado particular de gozo.

$\mathrm{Na}$ menina de que nos ocupamos vemos o paradoxo de um nome conservado feito com o Nome do Pai e um nome sem Nome do Pai feito gozo. Neste menina há um ponto de resistência à apropriação: seu nome. Este tem primordial importância e contribui à articulação entre o real do corpo e o simbólico. O nome é o primeiro fonema em relação à vida, é ele que a sustenta e é o significante em relação a seus pais, e será logo retomado por todos na sociedade.

A menina tem uma crise de choro quando escuta o nome pelo qual chamava seu pai, este apelo ao nome do pai devolve-a a uma legalidade na qual o desejo não se pode realizar sem lei.

A restituição opera um corte, uma vez que a tira de uma situação ominosa, produzindo um reordenamento simbólico que lhe permite definir seu lugar na ordem da descendência. Assim como o trabalho analítico, que inicia deixando em suspenso a escrita do nome e que lhe permite desdobrar, interrogar-se, construir e desconstruir a novela familiar e por último escrevê-lo, momento que coincide com outra escrita que é a oficial em seu documento de identidade.

Se nos relatos de Primo Levi e Jorge Semprún a escrita parece associada à vida e à morte, é porque é necessário um trabalho de historicização no qual a relação entre memória e esquecimento possa ser subjetivada no discurso.
O apelo das Avós da Praça de Maio - Abuelas de Plaza de Mayo - ao direito à identidade não é apenas o pedido de um ordenamento simbólico que responda à força da lei que, sendo igual para todos, funda uma comunidade ética e política. Insistir em restituir a estes jovens sua identidade implica o reconhecimento do vivido com o apropriador, do que foram privados com o assassinato de seus pais e de que isso é irrecuperável. Não se pode apagar magicamente a usurpação e as marcas que foram produzidas na subjetividade, mas sim pode-se abrir um espaço para construir uma verdade histórica que impeça o assassinato da memória. É dizer não às formas criminais de subjetivação, é tornar públicos atos que permaneceriam privados e ocultos, é exigir uma resposta jurídica e social.

O Estado terrorista fez do desaparecimento de pessoas seu principal recurso de gestão. Fazer desaparecer uma menina, despojá-la de sua família, de sua história, de seu nome, de seu corpo, de sua voz. Renegação de uma origem e de um ato que em sua persistência no social é renegação da renegação. Ao "desaparecê-la" para inscrevê-la como outra, produziu-se outro modo de filiação que é a otimização racional do encarceramento.

Vivemos na democracia, mas a ditadura não será algo ultrapassado enquanto houver jovens desaparecidos reaparecendo em outro sistema de parentesco. Walter Benjamin dizia que os homens voltam mudos de horror, sem nada para contar. Creio que as Avós da Praça de Maio, com seu trabalho, tratam de fazer inteligíveis os signos do horror em uma tentativa de sublinhar o caráter inenarrável do ocorrido ao manter viva sua memória como a de uma lição que não deve ser esquecida em tempos em que se suporta mal a memória do que ocorreu. 
No caso dessa menina, o trabalho analítico, ainda assim, permitiu-lhe entrar em contato com o que vivia sem saber, pois, sendo trabalho de memória e com a língua, permitiu-lhe significar até onde foi possível, para poder situar-se em outra posição subjetiva.

\section{REFERÊNCIAS BIBLIOGRÁFICAS}

Lacan, J. (1971). Función y campo de la palabra y el lenguaje. In Escritos 1. México: Siglo XXI, $2^{\mathrm{a}}$ ed. revisada.

(1988). Conferencia in Ginebra sobre el síntoma. In Intervenciones y Textos 2. Buenos Aires: Manantial.

Laurent, E. (1988). Estabilizaciones en las psicosis. Buenos Aires: Manantial.

Legendre, P. (1994). Lecciones VIII: "El crimen del cabo Lortie. Tratado sobre el padre". México: Siglo XXI.

México: Siglo XXI.

Levi, P. (1995). Si esto es un hombre. Espanha: Muchnik. (1989). Los bundidos y los salvados. Espanha: Muchnik.

Miller, J. A (1988). Algunas reflexiones sobre el fenómeno psicosomático. In Matemas II. Buenos Aires: Manantial.

Semprún, J. (1995). La escritura o la vida. Barcelona: Tusquets.

Soler, C. (1995). Los nombres de lo real. In Estudios de Psicosomática, 3.

\section{NOTAS}

1 No original, "bebés apropiados". A autora refere-se aos filhos de pais desaparecidos que foram seqüestrados e tiveram seus nomes e documentos adulterados. Foram roubados de seus pais por um outro que apropriou-se deles (N.T.).

2 Na Argentina a sigla NN é uma expressão usada para se referir as pessoas mortas cujo nome se desconhece.

3 A autora utiliza "apropriador" como aquele que realizou a apropriação tornando-se o "pai" da menina. Optamos por manter "apropriador", pois não encontramos um termo em português que pudesse substituir o original, mantendo a duplicidade de apropriador-pai (N.T.).

4 Parece tratar-se de um jogo inventado pela menina, que é importante na medida em que desencadeia a escrita do nome, conforme a autora descreve a seguir (N.T.).

5 A homofonia é entre "papa" e "papá" (papai) (N.T.). 